\title{
“Getting Used to Each Other": Immigrant Youth's Family Reunification Experiences
}

\author{
Carola Suárez-Orozco \\ New York University \\ Hee Jin Bang \\ William T. Grant Foundation
}

Ha Yeon Kim

\begin{abstract}
Many immigrant youth and their families undergo painful separations and complicated reunification experiences. Using data from the Longitudinal Immigrant Student Adaptation (LISA) study, a 5-year longitudinal, mixed-methods study of newcomer youth to the U.S., we examine the impact of lengthy family separations on youth's mental health and their perceived family conflict. Quantitative analyses demonstrate that longer separations positively predict higher psychological symptoms and family conflict, particularly for girls over a sustained period of time. Qualitative analyses of parent and child responses provide insights into the family reunification experiences.
\end{abstract}

Keywords : immigrant youth, migration, family separations, family conflict, mental health, gender

Worldwide, more than two hundred and fourteen million are immigrants and refugees. In the United States today, about $12 \%$ of population are foreign-born (U.S. Census Bureau, 2000), and more than a fifth of the nation's children are growing up in homes with at least one immigrant parent (Mather, 2009). During the course of migration, many families must make the painful decision to leave behind loved ones in their home countries, including children, spouses, and extended family members (United Nations Development Programme [UNDP], 2009). Thus, migration and forces of globalization are transforming family configurations (UNDP, 2009).

Increasingly, the experience of transnational

Corresponding Author: Carola Suarez-Orozco, Professor, Applied Psychology, Co-Director, Immigration Studies at NYU, NYU Steinhardt School of Culture, Education, \& Human Development, 726 Broadway, 5th Floor New York, NY 10003, USA E-mail: cso26@nyu.edu families can be characterized by "separation and reunification of different members of the family unit over time” (Tyyska, 2007, p. 91). When families separate, they generally expect to reunite quickly. However, in the process of migration, many endure prolonged periods of separation before reunification (Suárez-Orozco, Todorova, \& Louie, 2002). These family separation and reunification processes vary widely depending on the purposes of the migration as well as the social/cultural contexts of the families. Stepwise fashion migration is a common strategy for immigrant families (Hondagneu-Sotelo \& Avila, 1997; Orellana, Thorne, Chee, \& Lam, 2001). Historically, the pattern was of the father going ahead, establishing himself while sending remittances home, and then bringing the wife and children as soon as it was financially possible. Today, the first world's demand for service workers draw mothers from developing countries to care for "other people's children" 
(Gratton, 2007; Hondagneu-Sotelo, 2003). In cases where mothers initiate the migrations, they often leave their children in the care of grandparents or aunts along with the father if he is still part of the family. In other cases, both parents go ahead, leaving the children in the care of extended family (Bernhard, Landolt, \& Goldring, 2006; Qin \& Albin, 2010).

Reunification of the entire family can take many years, especially when complicated by financial hurdles as well as immigration laws (Menjívar \& Abrego, 2009). When it is time for the children to arrive, they may be brought to the new land all together or one at a time (Bernhard et al., 2006). Though parents maintain contact during the separation period through letters, phone calls, personal visits, and contributions to the material well-being of their children, these separation-reunification processes involve difficult psychological experiences for the children during the separation as well as after the reunification (Suárez-Orozco et al., 2002). For the children, these serial migrations result in two sets of disruptions in attachments - first from the parent, and then from the caretaker to whom the child has become attached during the parentchild separation (Ambert \& Krull, 2006; Wong, 2006).

This practice of “ 'familyhood' even across the national borders” (Bryceson \& Vuorela, 2002, p. 3) has largely failed to be noted in the developmental literature. In particular, the children's perspectives on the separation experience and its developmental implications have been overlooked until recently. Using a mixed-methods approach, this article examines links between disruptions of family systems and youth's psychological adjustment. It also presents insights into immigrant families' subjective experiences of the separationreunification process.

\section{Theoretical Frameworks}

Attachment theory. Though there is limited literature on the immigrant family separations and reunification experience, attachment theory provides a conceptual framework for understanding the processes involved. Attachment theorists argue that disruptions in affectional bonds with parental figures have profound psychological and developmental implications (Ainsworth, 1989; Bowlby, 1973; Lyons-Ruth, 1996). "An attachment figure is never wholly interchangeable or replaceable by another, even though there may be others to whom one is also attached. In attachments... there is a need to maintain proximity, distress upon inexplicable separation, pleasure or joy upon reunion, and grief at loss" (Ainsworth, 1989). The attachment with the mother or primary caretaker is thought to be of particular significance, though Ainsworth has argued that parent surrogates, siblings, and peers also may be extremely significant as attachment figures (Ainsworth, 1989).

Ambiguous loss. The literature on the experience of loss provides another frame for understanding the possible consequences of ruptures in parent-child relationships (Boss, 1999; Doka, 1989; Shapiro, 1994). Loss - which can result from death as well as a variety of other "exits" - is a transition that requires adaptation and may trigger a variety of physical, emotional, and behavioral responses. The response to what Boss has termed "ambiguous loss" is particularly relevant to parent-child separations during the migratory process (Boss, 1999). Ambiguous losses - when a loved one is either physically present but psychologically unavailable or when they are physically absent but psychologically present - may lead to complications in the resolution of grief. Since the parent(s) who leave(s) is/are not dead, but gone for what is often expected to be a short time, "permission" to grieve may not be granted. The child's loss may thus go unrecognized, leading to disenfranchised grief whereby silence surrounds the loss (Doka, 1989). Under such circumstances, the normal emotions of grieving - sadness, guilt, anger, and hopelessness - can be intensified because there is no specified arena in which to express these emotions.

To understand how losses affect children, it is critical to understand the way in which the adults 
in the child's circle as well as the wider culture react to the loss (Shapiro, 1994; Silverman, 2000). Grief triggers a crisis in family life that affects all members in some ways as they attempt to accommodate to the absence of a "vital member of an interdependent family" (Shapiro, 1994). Both the subjective individual experience, as well as the "systemic interweaving of grief reactions in the family, community, and culture," can influence family and individual development (Shapiro, 1994). If the remaining caretaker is overwhelmed with her own losses, she may not be available to the child to help contain his/her emotions. Critical to her well-being is the child's ability to keep the missing parent or caretaker psychologically present (Silverman, 2000). This process may best be served when the child is able to identify with a part of the loved one, thus maintaining an ongoing relationship even in their absence. If the child has continuity of care and someone who provides connection, the child is more likely to be able to make meaning of and accommodate to the loss (Silverman, 2000).

Family systems theory. Family systems theory is another useful theoretical frame for understanding transnational families particularly as we consider the reunification phase. Though intuitively it might seem that the period of separation would be the most difficult time and that the phase of reunification would be joyful and relatively uneventful, this phase, in fact, can be quite complicated (Falicov, 2007). After a lengthy separation, the child rejoins a family system that may include new family members (such as new siblings, step-parents, or extended family members). In addition, while in some cases, children leave a neutral or negative relationship with their caretaker in the home country, in others, they are removed from the tight, loving relationship with their caretaker and are in essence being forced to ambivalently enter into an unfamiliar family system with their biological parent upon re-unification. Therefore, a reunification process involves an adaptation period to a new family system, which should be understood in the context of interactions occurring within the family (Black, 2005). Family systems theorists argue that each member of the family influences and is influenced by the system (Bowen, 1978). Any disruptions within the family system has a ripple effect: when any one family member experiences significant losses, disruptions, or changes, dysfunctional behaviors or negative emotions may be displayed within the family system (Falicov, 1998). Thus, the stability of a family system may be affected by separations, reunifications, and other changes within the family circumstances (Fennell \& Weinhold, 1997; Minuchin, Colapinto, \& Minuchin, 1998).

Notably, the theoretical models discussed above have been developed within Western, OECD, English-speaking nations and thus were developed without reference to the cultural, social, economic, or psychological realities of what Arnett (2008) refers to as "the neglected 95\%" of the world's population. As a result, our frames of understanding may be somewhat limited by our expectations of what is 'normative' within Western families - mother, father, and child constellations (Bornstein, 2009). Further, these models of understanding do not take into consideration transnational immigrant families that exist in two country contexts - the native country of origin and the receiving context (in this case the U.S.) with two distinct sets of cultural values, norms, and expectations. Thus, responses to family separations can vary widely across cultures and manifest themselves in ways unfamiliar to Western-trained psychologists.

\section{Youth's Experience of Family Reunifications}

In this section, we briefly present findings from sociological, clinical, and developmental literature regarding impact of separations and reunifications on family relations and psychological experience, and their implication in youth adaptation in the host countries.

Changes in family relations. While the discipline of developmental psychology has been slow to realize the number of children and youth caught up in transnational family constellations, 
sociologists and clinical psychologists have been documenting this phenomenon over the last decade or so.

From the sociological data, several patterns emerge. The clearest evidence points to the disruption to family relations. In broad strokes, this research - based largely on transnational studies conducted on Central American and Mexican families during the separation phase in the country of origin and during the reunification stage in the receiving country - reveal some fairly consistent insights (Foner, 2009). During the separations phase, children appear to adjust more easily to the father being away, perhaps because this is consistent with gender expectations (Dreby, 2007). However, when the mother or both parents are away, the children often attach to the substitute caretaker. Mothers (more so than fathers) typically maintain regular contact with their children (Abrego, 2009; Dreby, 2006) attempting to sustain "emotional intimacy from a distance” (Dreby, 2006, p. 34). Younger children often begin to emotionally withdraw from their mothers, and adolescents typically become either quite independent or act out aggressively (Dreby, 2006; Smith, 2006). Thus, maintaining long-distance emotional intimacy over an extended physical absence is challenging. During the reunification stage, children and youth often report ambivalence about leaving behind their beloved extended family caretakers and friends and are anxious about meeting members of the biological family who have become strangers over the prolonged separation (Foner, 2009; Menjívar \& Abrego, 2009). Parents often report struggling to assert their authority and being frustrated that their financial and emotional sacrifices are not fully appreciated by their children (Menjívar \& Abrego, 2009; Zhou, 2009).

There is also a body of literature derived from clinical reports, which points to a pattern of family conflict during the family reunification phase (Glasgow \& Gouse-Shees, 1995; Sciarra, 1999). This literature suggests that over time, the family may have evolved in such a way that excludes the parent who has been away, making reunification difficult (Falicov, 2007; Partida,
1996). Parents tend to expect their children to be grateful for their sacrifices but often find that their children are ambivalent about joining their parents in the migratory process (Rousseau et al., 2009; Sciarra, 1999). Also, children may be disappointed for how their real parents turn out to be, compared to their fantasies and expectations about the life in the U.S. (Artico, 2003). After the long separation period, youth left behind feel competitive with siblings born in the host country for the mother's affection (Arnold, 2006), and parents often report having difficulties in establishing functional intra-family relations (Arnold, 2006; Sewell-Coker, Hamilton-Collins, \& Fein, 1985). The longer the separation they undergo, the less likely adolescents report being able to identify with their parents or be willing to conform to their rules at the time of reunification (Smith, Lalonde, \& Johnson, 2004). For parents, reestablishing control and authority may be complicated by guilt, which may result in inconsistencies and overindulgence (Arnold, 1991; Burke, 1980). A continual pattern of rejection and counterrejection may emerge, leading some families to seek treatment (Glasgow \& Gous-Shees, 1995). Thus, many reunified families experience tensions, conflict, and adjustment difficulties, particularly during the phase of adolescent development (Crawford-Brown \& Melrose, 2001; Lashley, 2000).

While the research from sociological and clinical perspective is useful, there is more to learn about the family separation phenomenon and its impact on immigrant youth's lives. Particularly, much of the richest sociological research on the phenomenon has been conducted only with mothers (e.g., Hondagneu-Sotelo \& Avila, 1997; Levitt, 2001) or with single country samples (e.g., Dominicans - Levitt, 2001; Mexicans - Dreby, 2007, 2009; Salvadorans Abrego, 2009). The clinical literature does not shed adequate light on understanding the effects of separations on generally functional families, as only those who are in need of treatment are represented. Moreover, to date, these studies have largely been qualitative. Thus, while we have some insights into the effects of 
transnationalism on immigrant families (Falicov, 2007; Foner, 2009), we know little about normative developmental outcomes for immigrant youth from diverse backgrounds.

Psychological consequences. Family contexts have been well established to have critical implications for the functioning of children and youth (Bronfenbrenner \& Morris, 1998; Small \& Covalt, 2006). Disruptions in family systems are likely to have implications for the well-being of children. A number of clinical studies (conducted with Caribbean families in Canada and Great Britain, along with a few studies on Caribbean and Latino families in U.S.) show that there are substantial negative psychological repercussions for immigrant children and youth who have been separated from their parents. These studies uniformly point to complications occurring both during the separation phase when the child is left with relatives and during the reunification phase when the child joins the parents. While apart from the parent, children and youth may feel abandoned and may respond with despair and detachment (Artico, 2003). Once reunified, they often miss those who have cared for them in their parent's absence as well as extended family members and friends (Arnold, 1991; Sciarra, 1999). Particularly when separations have been protracted, children and parents frequently report that they feel like strangers (Artico, 2003; Forman, 1993). Attachment difficulties have been noted (Wilkes, 1992), and children and youth are often withdrawn from the parents with whom they are reunited (Suárez-Orozco et al., 2002) and report low self-esteem at the time of reunion (Smith et al., 2004). Depressive responses have been noted in both children (Rutter, 1971) and mothers (Bernhard et al., 2006). Children may have difficulty trusting others (Arnold, 2006; Artico, 2003), and those who experienced long-term separations are more likely to receive psychiatric services (Morgan et al., 2007). Some youth may respond by externalizing, increased anger, and aggression (Dreby, 2007; Lashley, 2000; Smith, 2006). Thus, previous research suggests that while children and youth may be the "primary [intended] beneficiaries of their parents' sacrifice...[they] are often the last link to move abroad...[and] are left behind [to] pay the emotional price of separation from parents over the long run" (Dreby, 2007, p. 1051).

While these reports are important in delineating the syndrome and its clinical ramifications, they do not explain or help us better understand the consequences of separations of generally functional families. These studies, because they are derived from clinical populations, focus only on families and youth who are unsuccessful in managing the separations without clinical intervention. This presents the possible danger of overly pathologizing the outcome of separations. Indeed, Rouseau and colleagues (2009) found that the experience of extended separation is associated with psychological symptoms and suggested that post-migration reorganization of the family and interaction with the host society may have greater influence on successes and difficulties of adaptation in the host countries than the migration-related family separation itself.

Similarly, in analyses of the LISA study data, we found that children who were separated from their parents were more likely to report symptoms of anxiety and depression in the initial years of immigration than those who were not separated. Youths who had undergone the longest separations from their mothers reported the highest levels of anxiety and depression. Generally, the highest levels of distress were reported by youths who underwent mid- and long-term separations.

Gender differences among immigrant youth. Emerging findings in developmental literature suggest that there are gender differences in intergenerational conflict, particularly in relation to differences in parental control. Dion and Dion (2001) argue that since parents exert greater control on their daughters, girls may be more likely to resist or reject traditional beliefs or values. Some evidence shows that adolescent girls are less likely to endorse traditional family values (Rosenthal et al., 1996) and gender role ideology (Dasgupta, 1998; Tang \& Dion, 1999). 
Talbani and Hasanali (2000) found that South Asian girls in Canada disapprove of the strict parental control. They express their "suppressed frustrations” by not telling their parents, creating dissidence, alienation from parents, and sometimes open rebellion. These contradictions can create serious psychological stress in some girls. Research shows parallel findings in Hmong (Lee, 2001), Filipino (Espiritu, 2001), Korean (Hauh, 1999), Latino (Calderon, 1998), and Indian families (Pettys \& Balgopal, 1998) in the U.S. This pattern seems to hold up in international research as comparable findings are documented in immigrant families in Norway (Prieur, 2002) and South Asian families in Canada (Ghosh, 1984). Of course, immigrant parents have conflict with their sons as well. These conflicts, however, tend to center around issues of delinquent or problem behaviors (Gabaccia, 1994), and much less is written about generational conflict with boys. Even less is known about girls' and boys' experience in families that had lengthy separations, indicating a fertile avenue for future research.

\section{Overview of the current study}

In this study, we provide an indication of the scope of the family separations and reunification issue, reporting on the psychological experiences of youth who reunited with their parents after various lengths of family separation through triangulation of the analysis of quantitative and qualitative data. By examining developmental outcomes among a cohort of newcomer immigrants recruited from a non-clinical setting in public schools, this study affords us a view into youth and their families who have not sought treatment and are more typical of the immigrant experience.

The aims of this paper are several-fold. Utilizing quantitative data, we first test and validate relationships between variables. We (a) examine whether youth's perception of family conflict is predicted by length of separation from their parents, (b) investigate the relations between the lengths of separations and psychological symptoms at two time points, focusing on gender differences, and (c) test mediating role of family conflict in relations between length of separation and psychological symptoms. Finally, the analyses of qualitative data provide insights into youth's and parents' reunification experiences.

\section{Method}

This study utilized a subset of data from the Longitudinal Student Immigrant Adaptation (LISA) Study, a five-year longitudinal study that used interdisciplinary and comparative approaches to document patterns of adaptation among recently arrived immigrant youth from five sending origins arriving to two receiving centers in the U.S. (Suárez-Orozco et al., 2008).

Mixed-Methods Approach. LISA involved students from distinct languages and cultural backgrounds. Cross-cultural research with immigrants challenges traditional social science assumptions around validity and reliability (McLoyd \& Steinberg, 1998). Questions and prompts that are valid for one group may neither be valid nor culturally and linguistically unbiased for another group. Thus, we sought to apply quantitative and qualitative methods complementarily. Convergence emerging from this mixed-methods approach was likely to strengthen the validity of our findings (Bryman, 2004).

Our mixed-methods included structured individual interviews collected over the course of five years from students, parents, and school personnel. We sought to develop interviews that were relevant and equivalent across groups. As such, scale development was informed by bilingual/bicultural, "insider” research assistants in our protocol development team, their ethnographic fieldwork, and grounded emerging findings, thus building upon our mixed-methods synergetic foundations (Day, Sammons, \& Gu, 2008). Structured interviews were translated into Spanish, Haitian Creole, Mandarin, and Cantonese by bilingual research teams. These teams discussed each item of every scale to be 
included in the protocol. Wording was tweaked until there was agreement that the items were meaningful and appropriate. After translation, all scales were piloted with 5 adolescents from each group under consideration and then reviewed in the development team and modified as deemed appropriate.

\section{Participants}

Four hundred and seven immigrant youth participants (53\% female) recently arrived from Central America, China, the Dominican Republic, Haiti, and Mexico were initially recruited from the Boston and San Francisco metropolitan areas. We negotiated entrance into school sites with high densities of immigrant students and enlisted the help of school authorities to identify youth who met the inclusion criteria: both parents must be from one of the five regions of origin and students must have spent no more than a third of their lives in the U.S. Research assistants requested potential participants' involvement, assured them confidentiality, and obtained informed consent from parents. It is important to note that the LISA Study was not designed to include a representative sample of immigrant youth in the U.S. or in the two states (Massachusetts and California) where the study was conducted. Thus, we do not make claims about the generalizability of its findings to the larger immigrant youth population in the U.S. or to immigration in other countries.

Participants ranged in age from 9 to 14 at the beginning of the study ( $M=11.7$ years of age), though Haitians, on average, were significantly younger by one year than the Dominicans and Chinese. All participants had been in the U.S. less than a third of their lives ( $M=1.93$ years). By Year 5, the final sample included 309 students representing an attrition rate of 5\% annually. Two hundred and eighty two participants who participated in Year 5 survey and have separation data were included in the quantitative analyses presented in the current study (Chinese $=68$; Dominican = 54; Central American = 50; Haitian = 46; Mexican =64). Among the final sample (female $n=161,57 \%$ ), 67\% was living with two parental figures in Year $5(n=186) ; 66 \%$ had fathers who were employed ( $n=177)$, and $33 \%$ had mothers who at least had completed high school education $(n=89)$.

Additionally, twelve children who had undergone family separations were selected for in-depth interviews focused on their experiences of separations and reunifications. The group was balanced by gender and represented various types of separations, countries of origin, and patterns of separation (e.g., father only; mother only; and both; as well as varying lengths of separation).

\section{Procedures}

Students in the study were recruited from over 50 schools in 7 districts representing typical contexts of reception for newcomer students from each of the groups of origin (U.S. Census Bureau, 2000). Because of normative developmental school transitions (from middle to high school) and high mobility of immigrant students, our participants transferred schools frequently over the course of the 5 years of the study. By the end of the study, they had had dispersed to nearly 125 schools; students' transfer rates ranged between 1 and 5 transfer incidents $(M=2.4)$. Most of our students' schools were also highly racially and economically segregated. The schools they attended were characterized by high percentages of students living in poverty, with an average of $49.2 \%(S D=23.5 \%)$ of students receiving free or reduced-cost lunch. The minority representation rate at the schools our students attended was, on average, $78.8 \%(S D=23.2 \%)$. (See Suárez-Orozco et al., 2008 for detailed description of school contexts).

The study included structured interview data collected over the course of five years from students and parents. Each year, students completed structured interviews either during or after school, depending on the participant's availability and the activities occurring at school on the day of the interview. Bilingual RAs conducted all interviews orally on an individual 
basis in the participants' preferred language so that the quality of data was minimally affected by students' limited English language proficiency and/or literacy skills. Each student interview took about 1.5 to 2 hours to administer and involved a variety of question formats (openended, fill-in-the-blank, Likert scales, etc.). The questions in these interviews primarily provided the quantitative data used in the present study. Unfortunately, we were not able to administer all of the same questions in each year, given the burden on participants, the need to administer additional tests (e.g., standardized achievement and English language proficiency tests), and constraints on resources. Parent interviews included questions comparing life in the U.S. to the one in their countries of origin, their reasons for coming to the U.S., raising children in the new land, etc. and were conducted in the parents' native languages the first and last years of the study at the participants' homes. The majority of parents interviewed were mothers / maternal figures. (All interview protocols and other study instruments can be accessed at http:// steinhardt.nyu.edu/immigration/lisa).

\section{Quantitative Measures}

Separations from parents and lengths of separations. In the first year, parents were asked a series of questions about initial patterns of migration and the length of separations between children and parents. We examined the length of separation from each of the parental figures (length of separation from mother, length of separation from father), where lengths were categorized as follows: $0=$ no separation, $1=$ less than two years, 2 = two to four years, and 3 $=$ four years or longer.

Psychological symptoms. An 11-item psychological symptoms scale was developed by our cross-cultural and interdisciplinary research team, informed by the Diagnostic and Statistical Manual of Mental Disorders Fourth Edition (DSM-IV: American Psychiatric Association [APA], 1994) and the SCL-90 Questionnaire (Derogatis, 1977). The scale consists of two psychological symptoms that are theoretically related to separation experience: 6 items indicating depression (e.g., Lately do you: feel sad; feel not interested in much of anything) and 5 items indicating anxiety (e.g., Lately do you: feel nervous; feel tense). The questions were designed to be developmentally appropriate and cross-culturally relevant and piloted on informants at the same developmental level as our participants, representing each of the country of origin groups under consideration. We administered this measure in Year 1 and Year 5 (mean Cronbach's $\alpha=$.86). Scores ranged from 0 to 3 on each item, with higher scores signifying higher levels of depression and anxiety. The items on both scales were summed and averaged to create an overall internalization score.

Perceived family conflict. Youth's perceptions of family conflict were collected in Year 5. The 9-item scale created for the LISA Study asked students to describe how much they perceive issues at home which immigrant families often encounter as problems (e.g. parents don't understand what it is like to grow up in another country; parents don't like your friends). Items were scored on a 3-point Likert scale, with 1 indicating "not a problem" and 3 being " $a$ serious problem” (Cronbach’s $\alpha=.71$ ).

Socioeconomic factors and family composition. Data on demographic characteristics were derived from parent interviews. Since the mother's and father's education levels were highly correlated and there is evidence that mother's education is the best predictor of child outcomes (O’Connor \& McCartney, 2007), we focused on mothers' level of education data to gauge participants' socioeconomic status. We determined whether a student had a high school graduate mother (1) or not (0). Parental employment indicated whether at least one parent in the family was active in the workforce (1) or not (0). Family composition indicated that students were living with two or more adults (1) or with one or no adults in the home. 


\section{Qualitative Data Sources}

The qualitative data presented here were gathered from several sources: open-ended questions from the structured interviews conducted with the entire sample of 407 informants originally recruited for the LISA Study as well as their parents, data collected from the 282 students who reported a family separation; and follow-up in-depth interviews focused on separation with 12 students (selected from the 282) who had undergone separations. All this qualitative data focused on family separations and reunifications was collected only in Year 2.

Open-ended questions. In the first year of the study, parents were asked about their relationship with their child, and we found they often revealed information about their family separations and reunifications. Specifically, we asked: What kind of relationship did you have with your child before you came to the US? Has your relationship changed since you came to the US? In what ways? [If things have changed], what do you think are some of the reasons for these changes? After analyzing the first year data and realizing that such a large proportion of families had been separated during the course of migration, we added to the second year student interview several questions about the reunification process which were posed to all students who had experienced separations. These questions included: How did you feel when you were first reunited? Was there anything difficult or complicated about getting together? And how are things now?

Follow-up separations interviews. During the second year of the LISA project, we selected 12 children who had undergone lengthy separations. We interviewed the child and the parent (separately); each participated in extended semistructured, 1.5 to 2 hour-long interviews focused on their experiences of separations and reunifications. The interview explored the participants' experiences both during the separations as well as the reunifications phase.

Coding of all qualitative data. An open-

Table 1

Coding Categories of Qualitative Data

\begin{tabular}{|c|c|c|c|c|}
\hline & \multicolumn{2}{|c|}{ Girls } & \multicolumn{2}{|c|}{ Boys } \\
\hline & $n$ & $\%$ & $n$ & $\%$ \\
\hline Youth Concerns during Reunification & \multicolumn{2}{|c|}{$n=161$} & \multicolumn{2}{|c|}{$n=121$} \\
\hline \multicolumn{5}{|l|}{ Emotion at Reunification } \\
\hline Positive (e.g., happy, excited) & 88 & 55 & 56 & 45 \\
\hline Negative (e.g. frightened, sad, unhappy) & 34 & 21 & 22 & 18 \\
\hline $\begin{array}{l}\text { Mixed (e.g., happy to meet father but sad to leave } \\
\text { grandmother) }\end{array}$ & 38 & 23 & 44 & 36 \\
\hline Meeting a stranger & 42 & 26 & 26 & 22 \\
\hline Reported concerns with New Sibling & 24 & 15 & 17 & 14 \\
\hline Reported concerns with step-parent (or step-figure) & 34 & 21 & 26 & 21 \\
\hline Missing caretaker in country of origin & 82 & 51 & 57 & 47 \\
\hline Parent Concerns during Reunification & \multicolumn{2}{|c|}{$n=6$} & \multicolumn{2}{|c|}{$n=6$} \\
\hline Re-establishing authority & 4 & 66 & 5 & 83 \\
\hline Guilt & 3 & 50 & 3 & 50 \\
\hline
\end{tabular}


coding process using phrases as units of analysis was employed (Strauss \& Corbin, 1990). During the first stage of the coding, emergent descriptive themes from all of the transcripts were identified. The initial set of themes identified independently by two coders was compared and integrated into a comprehensive list of coding categories (Miles \& Huberman, 1994). Once these "pattern codes" (Miles \& Huberman, 1994, p. 67) were identified, a second iteration of coding was conducted using another analytic procedure. Examination of the pattern codes and the types of separations revealed insights into the processes and meanings of the separations and reunifications for youth and their families. Table 1 displays the coding categories focused on the reunification process.

The coders (who were not involved in the data collection process to guard against bias during the analytic and interpretative processes) refined the coding scheme "by discussing the meanings of, and relationships between, each coding category, and identified rules for determining when a particular coding category should be assigned to a response” (Mattis et al., 2008, p. 420-421). Two coders assessed the reliability of the coding scheme using $10 \%$ of randomly selected narrative samples. The formula for interrater reliability was: agreement/(agreement + disagreement) with a target rate of $85 \%$ reliability as the lowest acceptable level for each category (Miles \& Huberman, 1994). The software program ATLAS/ti was used to facilitate the inductive and deductive development and application of codes across data sources, as well as the creation of conceptual models.

\section{Quantitative Results}

We examined the descriptive statistics of the study variables and the correlations between them (See Table 2 for key descriptive statistics). To gain insights about developmental outcomes related to separation experiences, we examined relations between the length of separation from mother and father, youth's perceived family conflict, and their psychological symptoms.
Ramification of Family Separation in Youth's Perceived Family Conflict. A series of OLS regression models were run to examine the relationship between family conflict and length of separation from mother and father. Among the participants who had various lengths of separation from their mother (none, less than 2 years, 2 to 4 years, and more than 4 years), youth who experienced longer separations reported significantly higher levels of family conflict $(b=.70, p<.001)$ after controlling for gender, age, and family characteristics $\left(R^{2}=.13\right.$, $F=6.29, p<.001$ ) (See Table 3). Similarly, longer separations from father predicted youth's report of greater family conflict $(b=.62, p<.001$, $R^{2}=.08, F=6.29, p<.001$ ) (See Table 3).

Psychological Symptoms. Youth’s psychological symptoms related to family separation following the migration process were examined at two time points: about 2 years after migration (Year 1 ) and about 7 years after migration (Year 5). In Year 1 analyses, both length of separation from mother $(b=.08, p<.05)$ and length of separation from father ( $b=.14, p=.001$ ), respectively, predicted youth's psychological symptoms when gender, age, and family characteristics were controlled for. That is, youth who had longer separation from either of the parents were more likely to experience depression and anxiety symptoms. Age of the participant was a significant predictor in both separation from mother model $(b=-.08$, $p<.01)$ and separation from father model $(b=$ $.08, p<.01)$.

The analysis of psychological symptoms in Year 5 revealed differential patterns between youth who were separated from their mothers and those who were separated from their fathers (Table 4, Models 1 \& 3). In the model that examined the effect of separation from mother, length of separation significantly predicted Year 5 psychological symptoms ( $b=.08, p<.05)$, after age, gender, family characteristics, and Year 1 psychological symptoms were entered into the model $\left(R^{2}=.16, F=6.82, p<.001\right)$. In contrast, length of separation from father was not a significant predictor of youth's psychological symptoms in Year $5(b=.05, p=.26)$. 
“Getting Used to Each Other”: Immigrant Youth’s Family Reunification Experiences

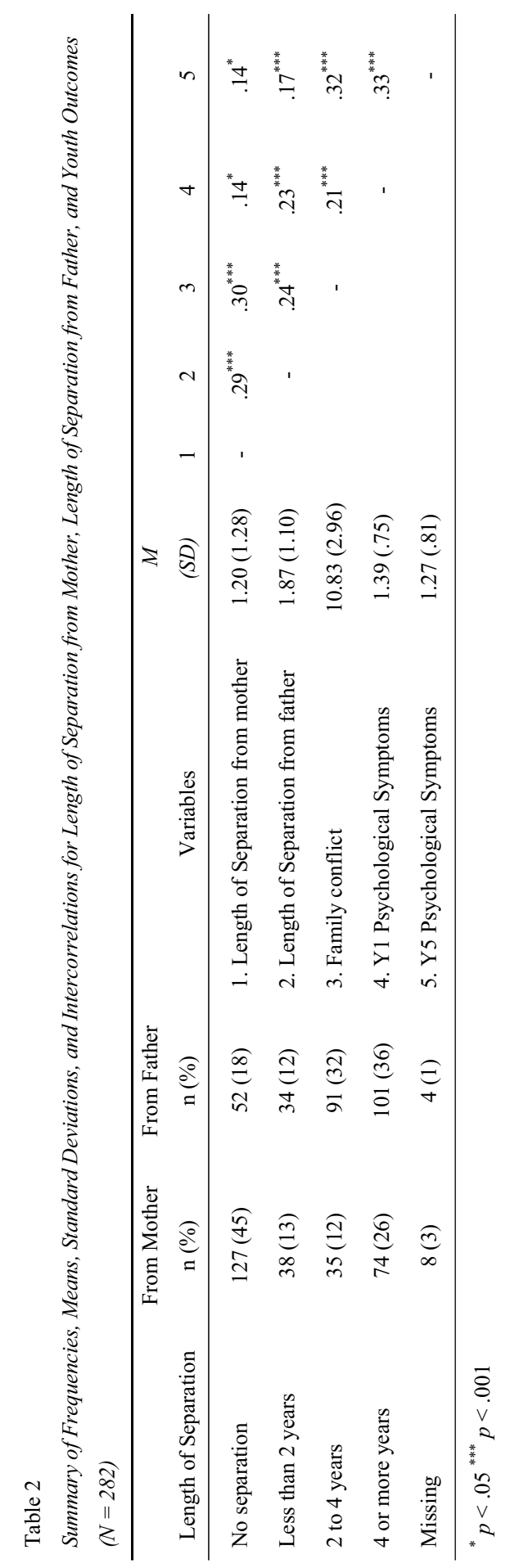

Child Studies in Diverse Contexts, 2011, 1(1) 
Table 3

Regression Model Predicting Immigrant Youth's Perceived Family Conflict

\begin{tabular}{|c|c|c|c|c|c|c|}
\hline & \multicolumn{6}{|c|}{ Parental figure youth separated from } \\
\hline & \multicolumn{3}{|c|}{ Mother } & \multicolumn{3}{|c|}{ Father } \\
\hline & $b$ & $\beta$ & $S E$ & $b$ & $\beta$ & $S E$ \\
\hline constant & $8.81^{* * * *}$ & $.00^{* * *}$ & 1.32 & $.00^{* * *}$ & $.00^{* * *}$ & 1.42 \\
\hline Student Gender & .01 & .00 & .34 & -.04 & -.04 & .35 \\
\hline Student Age & .13 & .07 & .11 & .08 & .08 & .11 \\
\hline Parental Employment & -.39 & -.07 & .50 & -.02 & -.02 & .52 \\
\hline Maternal Education & -.48 & -.08 & .36 & -.09 & -.09 & .37 \\
\hline Living with Two & -.18 & -.03 & .51 & -.01 & -.01 & .53 \\
\hline \multicolumn{7}{|l|}{ Parents in Year 5} \\
\hline Length of Separation & $.70^{* * *}$ & $.31^{* * *}$ & .13 & $.62^{* * * *}$ & $.24^{* * *}$ & .16 \\
\hline$R^{2}$ & & 0.13 & & & 0.08 & \\
\hline$F$ & & $6.29 * * *$ & & & $3.85 * * *$ & \\
\hline
\end{tabular}

${ }^{*} p<.05^{* * *} p<.001$

Gender Differences. Differential impact of separation experience to psychological symptoms among boys and girls $(b=.16, p<.05)$ were found among youth who experienced separation from their mothers (Table 4, Model 2). The results suggested that longer separation from mother predicted more negative psychological consequences for girls than for boys (Figure 1). However, the effect of length of separation from father did not have different impacts on boys and girls (Table 4, Model 4).

Family Conflict. Prior research on family systems theories and separations suggested that youth's experience of family conflict during unification phase may impact their psychological well-being. Therefore, we tested the hypothesis that family conflict will mediate the relations between length of separation from parents and youth's psychological symptoms in Year 5. We conducted a series of OLS regression models using the methods described by Baron and Kenny (1986), according to whom four assumptions need to be met to establish mediation. First, the independent variable must directly affect the dependent variable (path $c$ ). Second, the independent variable must directly affect the mediator (path $a$ ). Third, the mediator must affect the dependent variable (path $b$ ). Finally, after controlling for the mediator, the relationship between independent and dependent variables must be removed or reduced (path $c^{\prime}$ ). Because the findings suggested that length of separation from father was not a significant predictor of youth's psychological symptoms at Year 5, we conducted mediation analyses for separation from mother model only.

In the mediation analysis, length of separation from mother was an independent variable; Year 5 family conflict was the mediator; Year 5 psychological symptoms was the dependent variable; and participants' age, gender, family characteristics, and Year 1 psychological symptoms were covariates. All conditions described above were met (Figure 2). Length of separation from mother was a significant 
“Getting Used to Each Other”: Immigrant Youth’s Family Reunification Experiences

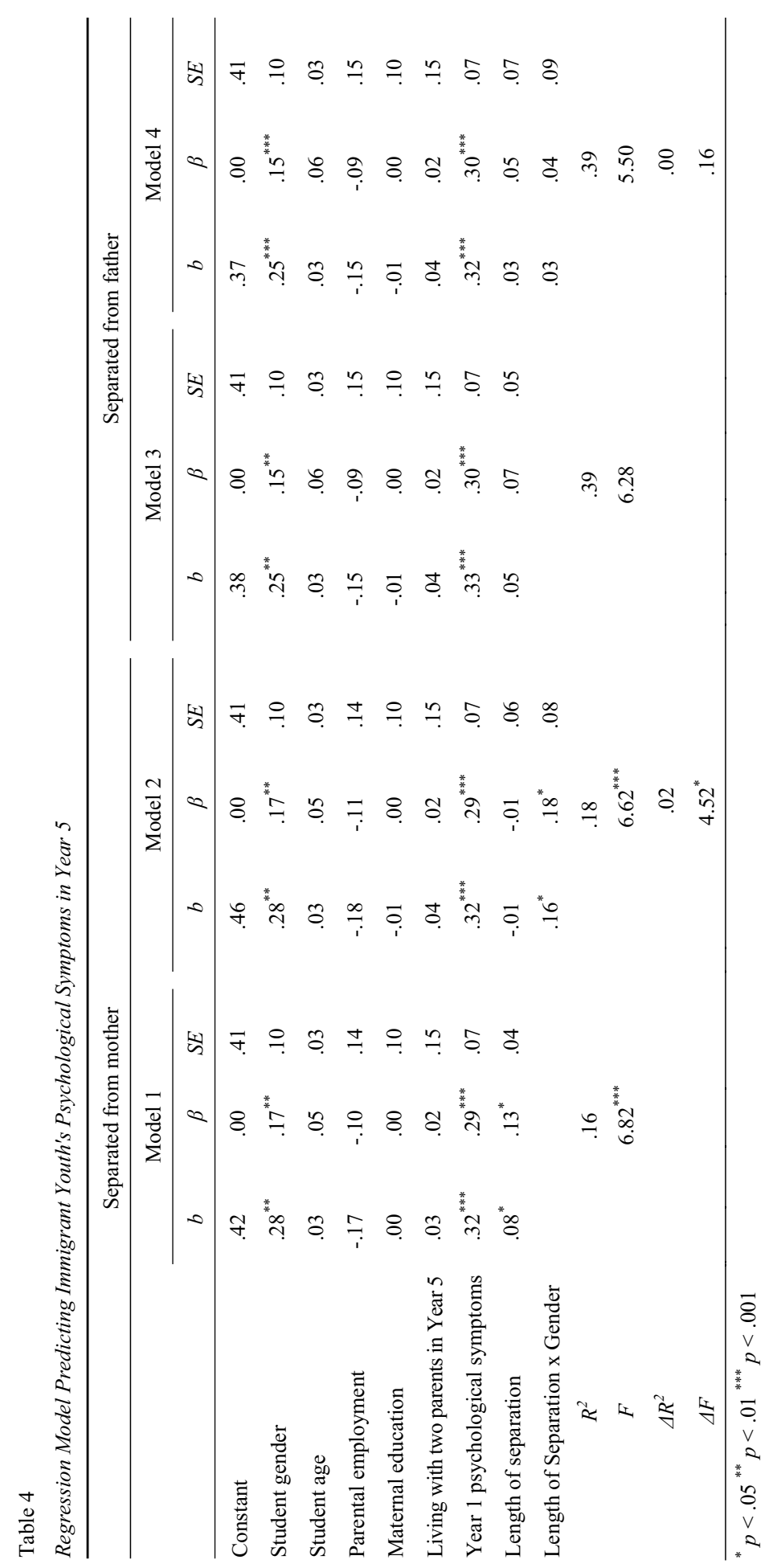

Child Studies in Diverse Contexts, 2011, 1(1) 


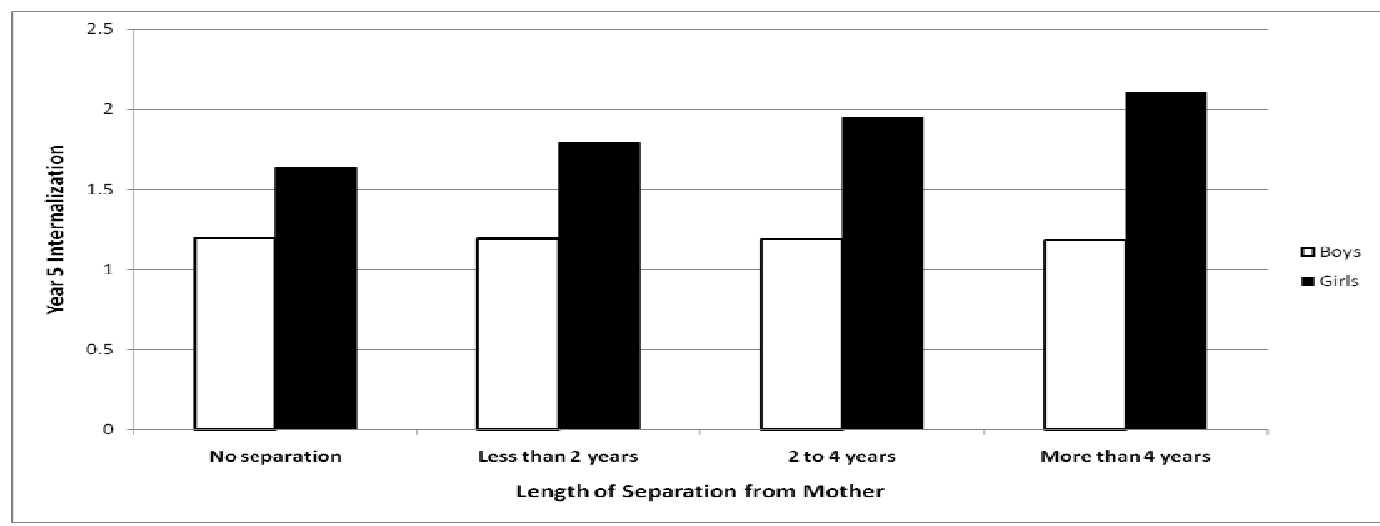

Figure 1. Mean differences between boys and girls in Year 5 psychological symptom predicted by length of separation from mother.

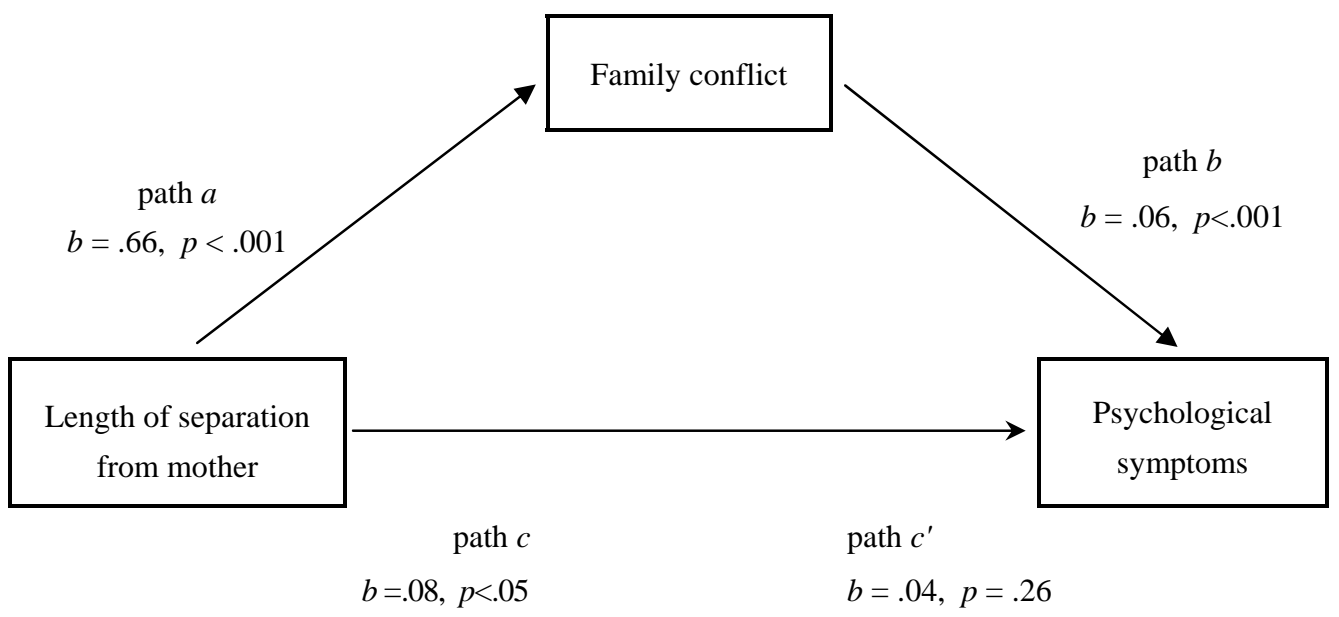

Note. Sobel's $z=2.79, p<.001$

Figure 2. Effect of length of separation from mother on Year 5 psychological symptoms completely mediated by family conflict

predictor of both family conflict (path $a, b=.66$, $p<.001$ ) and psychological symptoms (path $c, b$ $=.08, p<.05$ ). Family conflict was also a significant predictor of psychological symptoms (path $b, b=.06, p<.001$ ). When length of separation from mother and family conflict were entered simultaneously as predictors of psychological symptoms, the effect of length of separation from mother on psychological symptoms was removed (path $c^{\prime}, b=.04, p$ $=.26$ ), indicating that effect of length of separation on psychological symptoms was completely mediated by family conflict (Sobel's $z=2.79, p<.001)$. 


\section{Qualitative Results}

The challenges immigrant youth experience during family reunification emerged throughout our qualitative interviews both from the immigrant youth's and the parents' perspectives.

One might expect that the reunification would be a joyful experience. Indeed, many children, especially those who had short-term separations or who had been separated only from one parent while living with the other, described the moment of reunification with the modal word of: "happy”. A 13-year-old girl Guatemalan girl said that on the day she got together with her mother: "[I was] so happy. It was my dream to be with her." An 11-year-old Mexican boy said: "I was very happy to be with my parents again." Likewise, a Dominican 14-year-old girl described her family as they got together as: "We were so happy. We cried, talked a lot and embraced."

Meeting a stranger. Yet for many children who had endured protracted separations, the reunification was more complicated. In almost all cases, the children recalled that their parents, mothers in particular, received them in a highly emotional and tearful, welcoming manner. However, for the children, as new arrivals, the parent had become somewhat of a stranger. As a Guatemalan 14-year-old girl recalled, "My mother was crying. She hugged me... and I felt bad. Like neither my sister nor I knew her." Thus, for immigrant children, the reunification meant entering a new life in a new land, often with a new set of adults whom they would call mother and father, or parents whom they have not seen for a long time.

Feelings of disorientation emerged frequently from the data. As a 13-year-old Haitian girl shared: "I didn't know who I was going to live with or how my life was going to be. I knew of my father but I did not know him [the father]." Even under optimal circumstances, migrating to a different country and adopting a new way of life is likely to be disorientating. Yet for many youth in our study, this adaptation process was multiply complicated by the uncertainty about whether they would feel comfortable in their own homes, get along with the people they would be living with, and what their routines in the home would be like. In essence, many of these youth were not only migrating to a new land but also to a new family and lifestyle.

Often, the children reported not recognizing the parent and described difficulties in forging a relationship with a near stranger. A 10-year-old Chinese girl recalls: "The first time I saw my father, I thought he was my uncle ... I was really afraid when I saw my father's face. He looked very strict. I was unhappy. My father was a stranger to me." Similarly, a 13-year-old Guatemalan girl whose father left before her birth and whose mother left when she was a year old, not reuniting until 9 years later, told us:

I felt something very strange and since I didn't know my mother I would see a lot of women [at the airport] and I didn't know who was my mom. And when she came to hug me, I said to her, “Are you my mom?” I didn't hug her very strongly because I didn't know her or anything. I didn't have that much trust or didn't feel that comfortable with her.

Some parents perceived the lack of trust. The mother of a 14-year-old Honduran boy told us: "It was really hard at the beginning because we had been separated for 5 years. At the beginning, he barely trusted me, but now, little by little..." Thus, the effects of separation often lingered; the process of mending the relationship was a slow one.

In some cases, the predominant feeling expressed was of simple disorientation that needed time to heal. A 16-year-old Guatemalan girl, who had been separated since toddlerhood before reuniting with her mother 10 years later, told us: "It felt weird calling her mom.... Because I had called my grandparents mamí (mommy) and papí (daddy) for everything.” For other adolescents, the extended absence led to a sustained rejection of the parent whom they perceived to have had abandoned them. In such cases, the damage of the long absence led to rifts that seemed challenging to traverse. A 14-year- 
old Chinese girl confided that after a 9-year absence: "Suddenly I had another creature in my life called 'father'... I was too old by then and I could no longer accept him into my life.” For some youth, by the time parents reentered their life it was too late. These youth had grown accustomed to living without the missing parent; they were ready to assert greater independence and were unwilling to submit to the parents' authority after an extended absence.

Coming to terms with new family members. Parents and adolescents both reported that reunifications could be complicated when the youth had to adapt to an entirely new family constellation. Discomfort with living with new step-parents (or partners) or a new sibling (or step-siblings) was frequently noted by both participants and their parents. For example, this 12-year-old Mexican girl admitted that she had not wanted to migrate because: "I did not know anybody and I was going to live with a man [a new step-father] I did not like.” A 10-year-old Chinese girl confided that she had not “expect[ed] to live with a step-mother." Outright jealousy was also noted at times. The mother of a 13-year-old Nicaraguan boy disclosed:

We are getting used to each other. We are both beginning a different life together... [T] he kids are jealous of each other and my husband is jealous of them... Jealousy exists between those who were born here and those who were not. My son says, "You already spent a lot of time with her [his younger sister born in the U.S.].”

This family, like many others in our study, had to negotiate multiple new relations. The mother needed to build her relationship not only with each of her children, but also maintain a healthy marriage. Furthermore, she was to mediate her children's relationship with each other and the relationship between the children and her spouse. It was not unusual for the youth to particularly envy the attention lavished on new siblings (or step-siblings), which they had not received in their parent(s)' absence. As a 14-year-old Chinese girl articulately stated: "Now whenever
I see how my father spends time playing with my younger sister, I always get mad that he never gave me fatherly love. Now I think he is trying to make up to my younger sister." Such envy often led to tension and conflict between family members.

Missing caretakers in the homeland. While reunification was often described as a happy event, it was often interlaced with contradictory emotions. The grief of loss is often reexperienced again upon reunification, when the children had to leave the caretaker (often a grandparent or aunts and uncles) who became the symbolic parent during the absence of the parent. A 16-year-old Guatemalan girl explained:

I loved living with them [grandparents]

because they were really sweet people. They were wonderful parents.... [T]hey understand me, [and] they love me...I did not want to leave them. We [she and her siblings] were used to living with them.

Understandably, for many students in the study, the caretakers with whom they had daily physical contact had assumed an important role in their lives. This meant that for the migrating child, there was a bittersweet feeling upon reunification. A 16-year-old Guatemalan girl told us: "I was sad because I had left my grandparents behind but happy to be together with my mother and all.” Similarly, an 11-year-old Central American boy told us: "I was crying because I was leaving my grandfather. I had conflicting feelings. On the one hand I wanted to see my mother, but on the other I did not want to leave my grandfather." Such separations and connections to caretakers were major disruptions to which youth had to adapt.

Most of the participants expressed sadness and resignation about the loss of their caretaker in the country of origin though on occasion, anger was the prevailing emotion. A 14- year-old Chinese girl told us: "I felt like they tried to rob me away from my grandmother.... I always blame him for separating me and my grandmother.” A mother of a 9-year-old Mexican girl expressed the dilemma of missing parental figures succinctly: 
"Before she came, she missed us. Now she misses her grandparents.” In these families, the grandparents also endured two major separations. The elderly had said good-byes to their own children when the family migration to the U.S. began, and for a second time, they had to bid farewell to their grandchildren whom they had raised as their own children.

(Re)Establishing authority. Parents often expressed tremendous guilt for being away from their children while recognizing that their sacrifice was necessary for the good of the family. At the same time, it often dawned on them that their children did not always understand this. The longer the parents and child were apart, the harder it was for the child to make sense of the situation. Parental authority and credibility were undermined the longer the parent and the child were apart. An insightful mother of a 13-year-old Central American girl admitted:

Our relationship has not been that good. We were apart for eleven years....It's been difficult for her [my daughter] and for me. It's different for my son because I've been with him since he was born. If I scold him he understands where I'm coming from. He does not get angry or hurt because I discipline him but if I discipline her, she takes a completely different attitude than he. I think this is a normal way to feel based on the circumstance.

Children in such families likely perceived that their parents treated new siblings differently. This perception led to not only tensions between parent and child, but also to reported conflict between siblings and behavioral or emotional difficulties.

Resilience. Clearly, the migratory journey lead parents to make sacrifices to provide for their families; in the process, many were away for large portions of their children's formative years. For the children who underwent lengthy separations, the absent biological parent(s) began to fade to an abstraction over time. While parents were often appreciated and loved in their imagination, it was their daily caregivers who were their parents in reality. Children missed their parents, but most adapted to their caretaking situations, especially if it happened early in their childhood, was over a sustained period of time, and was in a caring environment. During the reunification phase, in the short term, both parents and children reported that reunification was difficult. This was especially true when the separation was a protracted one. Over time, however, most of the participants appeared remarkably resilient. A 14-year-old Nicaraguan boy summed up what seemed to be the experience of many: "The adaptation took a little time but we tried to get along and then little by little we became comfortable with one another.”

\section{Discussion}

Here we present evidence that separations between family members are frequent occurrences during the migratory journey. The majority of immigrant children in our sample, arriving from five countries of origin and recruited from the two coasts of the United States, had been separated from one or both parents. With well over $20 \%$ of children in the United States are growing up in immigrant homes, the implications for numbers of youth affected by this phenomenon is striking (Hernandez et al., 2007). Transnationally separated families are not unique to the U.S.-post-industrial nations the world over have experienced large scale migrations over the last decade (Gratton, 2007; UNDP, 2009). Furthermore, broad socioeconomic transformations have stimulated large-scale internal migrations within nations. Countries like China, India, and Turkey among others, have seen massive rural to urban migration bringing about similar patterns of displaced and separated families in disparate national settings (International Organization for Migration, 2008). Thus, a substantial number of children are being affected by family separation globally (UNDP, 2009). Understanding the implications for psychological wellbeing and family relations, 
therefore, should be of developmental interest.

In this non-clinical sample recruited from public schools, our findings provide evidence of the long-reaching ripples on both the psychological wellbeing of children as well as the family system. These findings are consistent with research from clinical settings suggesting that separations and reunifications may affect families who do not seek therapeutic services (Falicov, 2007). Quantitative analyses of the reported psychological symptoms reveal the long-lasting complications of the separation experience. In Year 1 (on average 2 years after reunification), youth who had undergone lengthier separations were more likely to report higher levels of both anxiety and depressive symptoms than those who had not been separated or who had only undergone short separations.

Encouragingly, previous research has revealed that by Year 5 (on average seven years after reunification) reported psychological symptoms had abated considerably for most youth (SuárezOrozco, Bang, \& Kim, 2011). Likewise, the qualitative interviews reveal that while parents and youth describe acute discomfort in the initial period following reunification, in most cases, they displayed strength, resourcefulness, and resilience in coping with the challenges imposed by separations and adjusting to new family constellations. Thus, while there were clearly adjustments and distress in the initial years of family reconfiguration, measurable psychological distress declined over time. Our findings suggest, therefore, that most newcomer immigrant youth gradually adjust to the loss and negative circumstances of separation resulting from migration. This result supports the research which demonstrates that many youth and families have a noteworthy capacity to overcome negative circumstances in their lives (Masten, 2001). It also serves as a reminder that it is important to consider the perspective of time in examining adaptations to adversity (Luthar \& Cicchetti, 2000).

The quantitative analyses of Year 5 psychological symptoms, however, revealed that children who underwent lengthy separations from their mothers reported higher levels of anxiety and depression symptoms than who had not been separated or underwent shorter separations. Further, both length of separation from mother as well as length of separation from father contributed to later family conflict. Thus, our results diverge from sociological studies that suggest that children appear to adjust more easily to the father being away (e.g., Dreby, 2007).

For girls in particular, the long-lasting psychological consequences seemed to be due to complications in family relationships. Psychological symptoms in Year 5 for girls depended primarily on how long they had been separated from their mothers and greater tension in the family. Higher level of family conflict mediated negative effects of lengthy separation on girls' psychological health, indicating that the long-term psychological ramification of lengthy separations is mainly due to the subsequent tense family relations. On the other hand, no effect of separation was found for boys' measurable internalizing psychological symptoms in Year 5. It is possible that negative effects of tense family relationships on boys manifest themselves in other ways not considered in the present set of analyses, such as physical health, academic performance, or involvement in externalizing behaviors. Prior research on gendered patterns in psychological health indicates that after early adolescence, females tend to handle conflict through internalizing the problems, while males tend to externalize the problems by engaging in delinquent activities (e.g., Rothbaum \& Weisz, 1994; Rosenfeld, 2002).

Analyses of qualitative data clarified the challenges of the process of reunification from children's and parents' points of view. Consistent with the findings of others (Charnley, 2000; Falicov, 2007), many children and youth report missing their caretakers back home. After lengthy separations, they are essentially meeting strangers at home while adjusting to a new land. Parents also struggle with their own ambivalence and guilt while attempting to reestablish authority over their children. Children and youth's ambiguous losses (Boss, 1999) resulting from these new separations and the 
turmoil of reunification) - create seismic waves through the family system which takes time for parents and children alike to come to terms with.

Our findings underscore the need for researchers and practitioners to collaborate and carefully consider individual student characteristics as well as their family configurations and histories in efforts to identify protective factors and ways to increase access to appropriate services and supports. Immigration is a stressful event. Difficulties include uprooting one's life, leaving one's family, friends, and social network, learning a new language and culture, among others. Evidence-based interventions should be developed with the aim of attenuating the effects of separation as well as developing strategies to help families manage the reunification process. Adapting to changes associated with migration requires determination and resiliency, and these are strengths many immigrant families and youth possess. Our qualitative data support the claim that immigrant families and youth have remarkable resiliency and capacity to overcome challenges that accompany migrations.

In general, it appears that for many immigrant youth, irrespective of culture of origin, separations cause angst that may create at least a temporary challenge to family relations and development. Many children and families report that the process is difficult and leads to a sense of longing and missing one another. Children and youth articulate missing loved ones - parents (during the separation phase) and caretakers (during the reunification phase). Nonetheless, transnational youths display notable resilience in the face of family separation. Moving forward, service providers and researchers should keep in mind the magnitude of the phenomenon of immigrant family separations. Further, while recognizing the short-term challenges such experiences present for families and youth, those serving immigrant communities should check their cultural biases, assumptions, and expectations of what a "typical" family looks like as immigrant families adapt to change.

Future Research. The present study focuses immigration to the U.S. To avoid imposition of ethnocentric outcomes, initial qualitative work with professionals in participants' country of origin, considering outcomes of concern noted within that context, would strengthen the constructs and instruments used. Culturally sensitive work should consider cultural norms of childcare and the meaning of collective values of family in different cultures that are closely related to family separation issues. While we found worrisome psychological and family outcomes, we also do not want to pathologize what is often a necessary family practice.

On a cautionary note, there are significant ethical landmines in conducting this kind of research, as participants are often both emotionally vulnerable when they speak of their significant losses as well as legally vulnerable, since they may not have achieved full documented status. Thus, researchers must proceed with extreme care in conducting research in this important domain affecting many families in our evermore-globalizing world.

\section{References}

Ainsworth, M. D. S. (1989). Attachments beyond Infancy. American Psychologist, 44(4), 709-716. doi: 10.1037/0003066X.44.4.709

Abrego, L. (2009). Economic well-being in Salvadoran transnational families: How gender affects remittance practices. Journal of Marriage and Family, 71, 1070-1085. doi: 10.1111/j.1741-3737.2009.00653.x

Ambert, A. M., \& Krull, C. (2006). Changing families: Relationships in context. Upper Saddle River, NJ: Pearson.

Arnett, J. J. (2008). The neglected 95\%: Why American psychology needs to become less American. American Psychologist, 63(7), 602-614. doi: 10.1037/0003-066X.63.7.602

Arnold, E. (1991). Issues of reunification of migrant West Indian children in the United Kingdom. In J. L. Roopnarine \& J. Brown (Eds.), Caribbean families diversity among ethnic groups (pp. 243-258). Greenwich, 
CN: Ablex Publishing Corp.

Arnold, E. (2006). Separation and loss through immigration of African Caribbean women to the UK. Attachment \& Human Development, 8(2), 159-174. doi: 10.1080/ 14616730600789472

Artico, C. I. (2003). Latino families broken by immigration: The adolescent's perceptions. New York: LFB Scholarly Publishing LLC.

Bernhard, J. K., Landolt, P., \& Goldring, L. (2006). Transnational, multi-local motherhood: Experiences of separation and reunification among Latin American families in Canada. CERIS, Policy Matters, 24. Retrieved July 15, 2009 from http://ceris.metropolis.net/PolicyMatter/ 2006/PolicyMatters24.pdf

Black, A. E. (2005). The separation and reunification of recently immigrated Mexican families. Walden University. A doctoral dissertation.

Bornstein, M. H. (Ed.). (2009). Handbook of cultural developmental science. New York, NY: Routledge.

Boss, P. (1999). Ambiguous loss: Learning to live with unresolved grief. Cambridge, MA: Harvard University Press.

Bowen, M. (1978). Family therapy in clinical practice. New York: J. Aronson.

Bowlby, J. (1973). Separation, anxiety and anger. New York: Basic Books.

Bronfenbrenner, U., \& Morris, P. A. (1998). The ecology of developmental processes. In R. M. Lerner (Ed.), Handbook of child psychology (5th ed.) (Vol. 1, pp. 993-1028). New York: Wiley.

Bryceson, D., \& Vuorela U. (2002). The transnational families in the twenty-first century. In D. Bryceson \& U. Vuorela (Eds.), The transnational family: New European frontiers and global networks (pp. 3-30). Oxford: Berg.

Bryman, A. (2004) Social research methods (2nd edition). Oxford: Oxford University Press.

Burke, A. W. (1980). Family stress and precipitation of psychiatric disorder: A comparative study among immigrant West
Indian and native British patients in Birmingham. International Journal of Social Psychiatry, 26(1), 35-40. doi: 10.1177/ 002076408002600105

Calderon, M. (1998). Adolescent sons and daughters of immigrants: How schools can respond. Yearbook-National Society for the Study of Education, 1, 65-87.

Charnley, H. (2000). Children separated from their families in the Mozambique war. In C. Panter-Brick \& M. T. Smith (Eds.), Abandoned children, (pp. 111-130). Cambridge: Cambridge University Press.

Crawford-Brown, C., \& Melrose, J. (2001). Parent-child relationships in Caribbean families. In N. Webb (Ed.), Culturally diverse parent-child and family relationships: A guide for social workers and other practitioners (pp.107-130). West Port, CT: Ablex.

Dasgupta, S. D. (1998). Gender roles and cultural continuity in the Asian Indian immigrant community in the U.S. Sex Roles, 38(11), 953-974. doi: 10.1023/ A:1018822525427

Day, C., Sammons, P., \& Gu, Q. (2008). Combining qualitative and quantitative methodologies in research on teachers' lives, work, and effectiveness: From integration to synergy. Educational Researcher, 37(6), 330-342. doi:10.3102/0013189X08324091

Derogatis, L. R. (1977). The SCL- 90 Manual I: Scoring administration and procedures for the SCL-90. Baltimore, MD: Johns Hopkins University School of Medicine.

Dion, K. K., \& Dion, K. L. (2001). Gender and cultural adaptation in immigrant families. Journal of Social Issues, 57(3), 511-521. doi:10.1111/0022-4537.00226

Doka, K. J. (1989). Disenfranchised grief: Recognizing hidden sorrow. New York, NY: Lexington Books.

Dreby, J. (2007). Children and power in Mexican transnational families. Journal of Marriage and Family, 69, 1050-1064. doi: 10.1111/ j.1741-3737.2007.00430.x

Dreby, J. (2006). Honor and virtue: Mexican parenting in the transnational context. 
Gender and Society, 20(1), 32-59. doi: $10.1177 / 0891243205282660$

Espiritu, Y. L. (2001). "We don't sleep around like White girls do”: Family, culture, and cender in Filipina American lives. Signs, 26(2), 415-440. doi: 10.1086/495599

Falicov, C. J. (2007). Working with transnational immigrants: Expanding meanings of family, community, and culture. Family Process, 46(2), 157-171. doi: 10.1111/j.15455300.2007.00201.x

Falicov, C. J. (1998). Latino families in therapy: A guide to multicultural practice. New York, NY: Guilford Press.

Fennell, D. L., \& Weinhold, B. K. (1997). Counseling families: An introduction to marriage and family therapy. Denver, CO: Love Publishing.

Foner, N. (2009). Introduction: Intergenerational relations in immigrant families. In N. Foner (Ed.), Across generations: Immigrant families in America (pp. 1-20). New York: New York University Press.

Forman, G. (1993). Women without their children: Immigrant women in the U.S. Development, 4, 51-55.

Gabaccia, D. R. (1994). From the other side: Women, gender, and immigrant life in the U.S., 1820-1990. Bloomington and Indianapolis: Indiana University Press.

Ghosh, R. (1984). South Asian women in Canada: Adaptation. South Asians in the Canadian mosaic, 145-155.

Glasgow, G. F., \& Gouse-Shees, J. (1995). Themes of rejection and abandonment in group work with Caribbean adolescents. Social Work with Groups, 4, 3-27. doi: 10.1300/ J009v17n04_02

Glick-Schiller, N. \& Fouron, G. (1992). "Everywhere we go, we are in danger": Ti Manno and the emergence of Haitian transnational identity. American Ethnologist, 17(2), 329-347. doi: 10.1525/ ae.1990.17.2.02a00080

Gratton, B. (2007). Ecuadorians in the United States and Spain: History, gender and niche formation. Journal of Ethnic and Migration Studies, 33(4), 581-599. doi: 10.1080/
13691830701265446

Hauh, P. (1999). Korean-American adolescents' perspectives on conflictual issues with their parents. Retrieved from http://worldcat. org/oclc/49660415

Hernandez, D., Denton, N., \& McCartney, S. (2007). Family circumstances of children in immigrant families: Looking to the future of America. New York: Guilford Press.

Hondagneu-Sotelo, P. (Ed.). (2003). Gender and U.S. immigration: Contemporary trends. Berkeley, CA: University of California Press.

Hondagneu-Sotelo, P., \& Avila, E. (1997). “I’m here, but I'm there": The meanings of Latina transnational motherhood. Gender \& Society, 11(5), 548-571. doi: 10.1177/ 089124397011005003

International Organization for Migration (2008). World migration. Geneva, IOM.

Lashley, M. (2000). The unrecognized social stressors of migration and reunification in Caribbean families. Transcultural Psychiatry, 37(2), 203-217. doi: 10.1177/ 136346150003700203

Lee, S.J. (2001). Exploring and transforming the landscape of gender and sexuality: Hmong American teenaged girls. Race, Gender and Class, 8(1), 35-46.

Levitt, P. (2001). The transnational villagers. Berkeley, CA: University of California Press.

Luthar, S. S., \& Cicchetti, D. (2000). The construct of resilience: Implications for interventions and social policy. Development and Psychopathology, 12, 857-885.

Lyons-Ruth, K. (1996). Attachment relationships among children with aggressive behavior problems: The role of disorganized early attachment patterns. Journal of Consulting Clinical Psychology, 64(1), 64-73. doi: 10.1037/0022-006X.64.1.64

Masten, A. S. (2001). Ordinary magic: Resilience processes in development. American Psychologist, 56(3), 227-238. doi: 10.1037/ 0003-066X.56.3.227

Mather, M. (2009). Children in immigrant 
families chart new path. Washington, D.C.: Population Reference Bureau. Retrieved from http://www.prb.org/pdf09/ immigrantchildren.pdf

Mattis, J. S., Grayman, N. A., Cowle, S., Winston, C., Watson, C., \& Jackson, D. (2008). Intersectional identities and the politics of altruistic care in a low-income, urban community. Sex Roles, 59, 418-428. doi: 10.1007/s11199-008-9426-2

McLoyd, V. C., \& Steinberg, L. D. (1998). Studying minority adolescents: Conceptual, methodological, and theoretical issues. Mahwah, NJ: Taylor \& Francis.

Menjívar, C., \& Abrego, L. (2009). Parents and children across borders: Legal instability and intergenerational relations in Guatemalan and Salvadoran families. In N. Foner (Ed.), Across generations: Immigrant families in America. (pp. 160189). New York: New York University Press.

Miles, M. B., \& Huberman, M. A. (1994). Qualitative data analysis: An expanded sourcebook (2nd ed.). Thousand Oaks, CA: Sage Publications.

Minuchin, P., Colapinto, J., \& Minuchin, S. (1998). Working with families of the poor. New York: Guilford Press.

Morgan, C., Kirkbride, J., Leff, J., Craig, T., Hutchinson, G., McKenzie, K., et al. (2007). Parental separation, loss and psychosis in different ethnic groups: A case-control study. Psychological Medicine, 37, 495-503. doi: 10.1017/S0033291706009330

O’Connor, E., \& McCartney, K. (2007). Examining teacher- child relationships and achievement as part of an ecological model of development. American Educational Research Journal, 44(2), 340-369. doi: 10.3102/0002831207302172

Orellana, M. F., Thorne, B., Chee, A. E., \& Lam, W. S. E. (2001). Transnational childhoods: The participation of children in processes of family migration. Social Problems, 48(4), 572-591. doi: 10.1525/sp.2001.48.4.572

Partida, J. (1996). The effects of immigration on children in the Mexican-American community. Child and Adolescent Social Work Journal, 13, 241-254. doi: 10.1007/BF01875790

Pettys, G. L., \& Balgopal, P. R. (1998). Multigenerational conflicts and new immigrants: An Indo-American experience. Families in Society, 79(4), 410-423.

Prieur, A. (2002). Gender remix. Ethnicities, 2(1), 53-77. doi:10.1177/1469682002002001522

Qin, J., \& Albin, B. (2010). The mental health of children left behind in rural China by migrating parents: A literature review. Journal of Public Mental Health, 9(3), 4-16. doi: 10.5042/jpmh.2010.0458

Rosenfeld, R. A. (2002). What do we learn about differences from the scholarship on gender? Social Forces, 81(1), 1-24.

Rosenthal, D., Ranieri, N., \& Klimidis, S. (1996). Vietnamese adolescents in Australia: Relationships between perceptions of self and parental values, intergenerational conflict, and gender dissatisfaction. International Journal of Psychology, 31(2), 81-91. doi: 10.1080/002075996401106

Rothbaum, F., \& Weisz, J. R. (1994). Parental caregiving and child externalizing behavior in nonclinical samples: A meta-analysis. Psychological Bulletin, 116(1), 55-74. doi:10.1037/0033-2909.116.1.55

Rousseau, C. I., Hassan, G., Measham, T., Moreau, N., Lashley, M., Castro, T., \& McKenzie, G. (2009). From the family universe to the outside world: Family relations, school attitude, and perception of racism in Caribbean and Filipino adolescents. Health \& Place, 15(3), 751760. doi:10.1016/j.healthplace.2008.12.004

Rutter, M. (1971). Parent-child separation: Psychological effects on the children. Child Psychology and Psychiatry, 12, 233-260. doi: 10.1111/j.1469-7610.1971.tb01086.x

Sciarra, D. T. (1999). Intrafamilial separations in the immigrant family: Implications for cross-cultural counseling. Journal of Multicultural Counseling and Development, 27(18), 30-41.

Sewell-Coker, B., Hamilton-Collins, J., \& Fein, E. (1985). West Indian immigrants. Social 
Casework, 60, 563-568.

Shapiro, E. R. (1994). Grief as a family process: A developmental approach to clinical practice. New York: Guilford Press.

Silverman, P. R. (2000). Never too young to know. NY: Oxford University Press.

Small, S., \& Covalt, B. (2006). The role of the family in promoting adolescent health and development: Critical questions and new understandings. In F.A. Villarruel \& T. Luster (Eds.), The crisis in youth mental health. Connecticut: Praeger Perspectives.

Smith, A., Lalonde, R. N., \& Johnson, S. (2004). Serial migration and its implications for the parent-child relationship: A retrospective analysis of the experiences of the children of Caribbean immigrants. Cultural Diversity and Ethnic Minority Psychology, 10(2), 107-122. doi: 10.1037/10999809.10.2.107

Smith, R. (2006). Mexican in New York: Transnational lives of new immigrants. Berkeley: University of California Press.

Suárez-Orozco, C., Bang, H. J., \& Kim, H. Y. (2011). I felt like my heart was staying behind: Psychological implications of family separations \& reunifications for immigrant youth. Journal of Adolescent Research, 26(2), 222-257. doi: 10.1177/ 0743558410376830

Suárez-Orozco, C., Suárez-Orozco, M. M., \& Todorova, I. (2008). Learning a new land: Immigrant students in American society. Cambridge, MA: Harvard University Press.

Suarez-Orozco, C., \& Qin, D. B. (2006). Gendered perspectives in psychology: Immigrant origin youth. International Migration Review, 40 (1), 165-198. doi: 10.1111/j.1747-7379.2006.00007.x

Suárez-Orozco, C., Todorova, I., \& Louie, J. (2002). "Making up for lost time:" The experience of separation and reunification among immigrant families. Family Process, 41(4), 625-643. doi: 10.1111/j.15455300.2002.00625.x

Talbani, A., \& Hasanali, P. (2000). Adolescent females between tradition and modernity: Gender role socialization in South Asian immigrant culture. Journal of Adolescence, 23(5), 615-627. doi:06/jado.2000.0348

Tang, T. N., \& Dion, K. L. (1999). Gender and acculturation in relation to traditionalism: Perceptions of self and parents among Chinese students. Sex Roles, 41, 17-29. doi: 10.1023/ A:1018881523745

Tyyska, V. (2007). Immigrant families in sociology. In J. E. Lansford, K. D. DeaterDeckard, \& M. H. Bornstein (Eds.), Immigrant families in contemporary society (pp. 83-99). New York: Guilford Press.

United Nations Development Programme (2009). Human development report 2009 Overcoming barriers: Human mobility and development. New York: United Nations Development Programme.

U.S. Census Bureau (2000). Census 2000 summary. Retrieved June 1, 2009 from http://factfinder.census.gov/servlet/ QTTable?_bm=y\&-geo_id=01000US\&qr_name=DEC_2000_SF3_U_QTP22\&ds_name=DEC_2000_SF3_U

Wilkes, J. R. (1992). Children in limbo: Working for the best outcome when children are taken into care. Canada's Mental Health, 40, 2-5.

Wong, B. P. (2006). Immigration, globalization and the Chinese American family. In J. E. Lansford, K. D. Deater-Deckard, \& M. H. Bornstein (Eds.), Immigrant families in contemporary society. New York: Guilford Press.

Zhou, M. (2009). Conflict, coping, and reconciliation: Intergenerational relations in Chinese immigrant families. In N. Foner (Ed.), Across generations: Immigrant families in America. (pp. 21-46). New York: New York University Press.

Received January 25, 2011

Revision Received June 13, 2011 Accepted July 5, 2011 